\title{
EDITORIAL
}

\section{A standard from the classical period}

\section{W O Myers}

New developments in bypass grafting and percutaneous interventions should increase the safety and tolerability of coronary revascularisation. But how long does the benefit last?

Correspondence to: Dr William O Myers, Marshfield Clinic 1000 North Oak Avenue, Marshfield, WI 54449,

USA; myers.william@ marshfieldclinic.org
D ating from the late 1960s, coronary artery bypass grafting $(\mathrm{CABG})$ remained a standard practice for a good 30 years. Percutaneous approaches came along halfway through that period, but the CABG operation did not change much. The widespread adoption of the internal thoracic artery (ITA) conduit to supply the left anterior descending coronary artery was the most significant modification, but was itself a return to pioneer work in the field.

Coronary artery intervention is currently changing almost by the day. Now CABG with minimally invasive and increasingly off-pump application fills the programmes of surgical scientific meetings. We hear about the possibility of non-sewn anastomoses, and hints of robotic surgery somewhere over the horizon. Plain old balloon angioplasty is entering the arena of multivessel disease, and is rapidly being supplanted by intracoronary stenting. New stent materials and new stent coatings are continually coming on line. Temporary filter devices are being developed to catch debris stirred up by manipulating a degenerating vessel. Antiplatelet and other new drugs are being utilised to prevent subsequent stenosis. All these new developments should increase the safety and tolerability of getting one's coronary arteries opened. The question is: how long does the benefit last? And how do the new techniques compare with what we did before?

This issue of Heart presents a population based study by Bradshaw and colleagues on their experience during 13 years of CABG service ( 1980 to 1993). ${ }^{1}$ Significantly, the report covers a stable population in Western Australia that had only one centre, the Royal Perth Hospital, supplying all CABG services. Such an area of relative isolation with a single source for high level service is ideal for population based outcome studies. This is something we have attempted here in northern Wisconsin with the Marshfield epidemiologic study area, where most medical care is from an integrated source. ${ }^{2}$

The Perth authors have accomplished the integration of Western Australian data by merging Perth CABG data with the Western Australia Health Services linked database (including hospital morbidity for acute admissions and specific disease registers) and the Australian National Death Index. They found only two late deaths that occurred outside Western Australia. They give us up to 20 years of follow up which, along with other long range studies they cite, provides a gold standard by which the new methods of coronary artery intervention will need to be measured.

\section{OPERATIVE MORTALITY AND MORBIDITY}

The authors start their follow up from the best possible starting point: an excellent operative mortality (OM) and morbidity. The Perth surgeons were able to achieve $1 \%$ OM early on. The coronary artery surgery study (CASS) registry enrolment started seven years earlier, and was completed two years before their study began. Several CASS centres experienced the same low OM rate as they reported for their earliest years. ${ }^{3}$ The Emory angioplasty versus surgery trial study ran from several of the same years as the Perth paper, and also reports a $1 \%$ OM in both CABG and percutaneous transluminal coronary angioplasty (PTCA). ${ }^{4}$ The Perth mortality experience worsened, although still below 3\%, by 1993. In contrast, the Society of Thoracic Surgeons database shows an improving mortality rate over time, although not dropping below 3\% until 1999. ${ }^{5}$ The Perth authors believe that operating upon increasingly older and sicker patients, and the widespread use of angioplasty in lower risk patients in the later years, accounted for their unfavourable trend.

The Perth and CASS survival curves are nearly superimposable. ${ }^{6}$ The CASS overall survival at 15 years was $56 \%$, and the Perth male survival was $56 \%$ at 15 years. Women gained slightly on the men in CASS, and had a bit better late survival than the men, but they fell behind the US age and race matched general female population. Late survival in the Perth women never caught up with that of the Perth men.

For a comparison group in the recent CASS surgical registry report, we used the device of age, sex, and race matched data from US population life tables. From this, we were able to suggest prognoses, including a relatively better prognosis for older patients than younger patients. Bradshaw also shows long term survival by age group with the expected steeper survival dropoff by increasing age, and shows less effect of age on event-free survival, but does not include a standard population comparison. Such a comparison, though rarely presented, would have been interesting and would serve as a reminder that fixing the coronaries does not restore the average longevity found in the general population.

Abbreviations: $C A B G$, coronary artery bypass grafting; CASS, coronary artery surgery study; OM operative mortality; PTCA, percutaneous transluminal coronary angioplasty; ITA, internal thoracic artery 


\section{IMPROVED SURVIVAL WITH ITA BYPASS}

Bradshaw does demonstrate the improved survival conferred by ITA bypass. In the CASS report, we used hazard function analysis (Blackstone) to determine when the hazard curve for CABG patients rises above that of the age, sex, and race-matched general population. We found that 10 or 12 years passed before experiencing a greater risk in ITA recipients, compared to about four years in non-ITA patients. The CASS report also shows how powerful patient baseline traits, such as diabetes, hypertension, and smoking are as survival predictors. The Perth databases were unable to supply such baseline trait information. Nonetheless, the Perth report, among others, will serve as a gold standard to be emulated by future studies of the newer coronary artery interventions.

Other studies have assessed the risks of coronary artery interventions as well. In 1992, Dargie summarised the results of the European coronary surgery study, ${ }^{7}$ Veterans Administration data, and the CASS data, and analysed the risk of cardiac events post-CABG compared to apparently normal men. He then drew implications with regard to airline pilot and aircrew licensing: "Thus the risk of a cardiac event in apparently normal men between the ages of 30 and 59 years ranges from 0.3 to $1.0 \%$ per annum. The risk of an incapacitating event in patients with the clinical characteristics of aviators without previous MI is $1.6 \%$ per annum post-surgery."

The new patient friendlier technology, which competes most directly with "classical" coronary bypass, is multivessel (mostly two artery) angioplasty with intracoronary stenting. The Emory angioplasty versus surgery trial, ${ }^{4}$ the bypass angioplasty revascularisation investigation, ${ }^{8}$ the random intervention treatment of angina study, ${ }^{9}$ and the arterial revascularization therapy study ${ }^{10}$ are all randomised studies of CABG versus PTCA. The conclusion one derives from these studies is that initial results with PTCA compare favourably with CABG. However, late results are as good as CABG only by allowing for late repeat percutaneous procedures, including subsequent stent placements and CABG when needed. By inspecting the report figures, survival over 2.5 to 5 years drops off at $1-2 \%$ per year in both trial arms, similar to the attrition in the large CABG only reports.

It appears from the recent randomised PTCA versus CABG trials that favourable patients will achieve a similar long term outcome post-PTCA with intracoronary stenting, if the re-stenosis problem is solved. A recent very large retrospective risk adjusted study of CABG versus stenting shows equal results in patients suitable for either approach. ${ }^{11}$ The primary angioplasty versus stent implantation in acute myocardial infarction $^{12}$ and the Belgium and Netherlands stent ${ }^{13}$ trials compared stent implantation with balloon angioplasty alone. Both show a reduced incidence of cardiac events in the stent groups with significantly lower restenosis rates.

\section{REPEAT PTCA OR STENTING}

The need for repeat PTCA or stenting may be more acceptable to patients than initial CABG, even though the latter may ultimately be required. Perhaps putting off CABG a few years will avoid the second CABG. The Hayes Inc online medical technology directory, sponsored by the insurance industry, gives an " $\mathrm{A}$ " rating to elective stent implantation and elective stent implantation using antiplatelet treatment. Thus, from a health insurance prospective, these procedures are becoming accepted standards of care in medical practice.

The Perth report is unusual in reporting the time to repeat bypass in a large group of patients. Mean time to a repeat CABG in their patients was 8.1 years, ranging up to 16 years. We found at Marshfield (unpublished thoracic and cardiovascular surgery departmental database information) that the average time to second CABG was just over nine years the first time we looked at it. However, at 22 years into the CABG era the average time to second CABG was 11 years. We suggest that average time to repeat CABG is a moving target. We presume that this is the reason why Bradshaw uses a three year point to compare the effects of available baseline traits on incidence of reoperation.

Nonetheless, the risk of needing a repeat operation is a reality whether using CABG or PTCA with or without stent placement. For three vessel disease, multiple or diffuse lesions, left main coronary artery stenosis, and impaired left ventricular function, CABG which includes at least one ITA bypass remains the most common treatment at this time, the results of which still set a high standard.

\section{REFERENCES}

1 Bradshaw PJ, Jamrozik K, Le M, et al. Mortality and recurrent cardiac events after coronary artery bypass graft: long term outcomes in a population study. Heart 2002;88:488-94

2 DeStefano F, Eaker ED, Broste SK, et al. Epidemiologic research in an integrated regional medical care system: the Marshfield epidemiologic study Area. J Clin Epidemiol 1996:49:643-52.

3 Kennedy JW, Kaiser GC, Fisher LD, et al. Clinical and angiographic predictors of operative mortality from the collaborative study in coronary artery surgery (CASS). Circulation 1981;63:793-802.

4 King SB 3rd. The impact of performing a clinical trial on patient outcomes: lessons from the Emory angioplasty vs. surgery trial. Trans Am Clin Climatol Assoc 1995;107:68-77.

5 Society of Thoracic Surgeons. Data analysis of the Society of Thoracic Surgeons National Adult Cardiac Surgery Database, 2001 http://www.ctsnet.org/doc/5456

6 Myers WO, Blackstone EH, Davis K, et al. CASS registry long term surgical survival. Coronary artery surgery study. J Am Coll Cardiol 1999;33:488-98.

7 Dargie HJ. Late results following coronary artery bypass grafting. Eur Heart J 1992;13(suppl H):89-95

8 BARI Investigators. Five-year clinical and functional outcome comparing bypass surgery and angioplasty in patients with multivessel coronary disease. A multicenter randomized trial. Writing group for the bypass angioplasty revascularization investigation (BARI) investigators. JAMA 1997;277:715-21.

9 RITA Investigators. Coronary angioplasty versus coronary artery bypass surgery: the randomised intervention treatment of angina (RITA) trial. Lancet 1993;341:573-80.

10 Abizaid A, Costa MA, Centemero M, et al. Clinical and economic impact of diabetes mellitus on percutaneous and surgical treatment of multivessel coronary disease patients: insights from the arterial revascularization therapy study (ARTS) trial. Circulation 2001;104:533-8

11 Villareal RP, Lee VV, Elayda MA, et al. Coronary artery bypass surgery versus coronary stenting: risk-adjusted survival rates in 5,619 patients. Tex Heart Inst J 2002;29:3-9.

12 Saito S, Hosokawa G, Tanaka S, et al. Primary stent implantation is superior to balloon angioplasty in acute myocardial infarction: final results of the primary angioplasty versus stent implantation in acute myocardial infarction (PASTA) trial. PASTA trial investigators. Catheter Cardiovasc Interv 1999:48:262-8.

13 Kiemeneij F, Serruys PW, Macaya C, et al. Continued benefit of coronary stenting versus balloon angioplasty: five-year clinical follow-up of Benestent-I trial. J Am Coll Cardiol 2001;37:1598-603. 